\title{
Preparation Nano-Diamond Film by Sol-Gelled Coating Method for Field Emission Display
}

\author{
Xiuxia Zhang ${ }^{1,2^{*}}$, Shuyi Wei ${ }^{1}$, Qianyu Ji1 \\ ${ }^{1}$ School of Electrical and Information Engineering, Beifang University of Nationalities, Yinchuan, China \\ ${ }^{2}$ Optoelectronic Information Engineering, Hefei University of Technology, Hefei, China \\ Email: *xxuazh@126.com
}

How to cite this paper: Zhang, X.X., Wei, S.Y. and Ji, Q.Y. (2017) Preparation NanoDiamond Film by Sol-Gelled Coating Method for Field Emission Display. Advances in Nanoparticles, 6, 1-9.

https://doi.org/10.4236/anp.2017.61001

Received: November 9, 2016

Accepted: February 7, 2017

Published: February 10, 2017

Copyright $\odot 2017$ by authors and Scientific Research Publishing Inc. This work is licensed under the Creative Commons Attribution International License (CC BY 4.0).

http://creativecommons.org/licenses/by/4.0/

\begin{abstract}
The mixture of Nano-graphite and organic vehicles doped to Nano-diamond paste. The suitable paste proportion was found. Nano-diamond film (NDF) was prepared by sol-gel coating method on ITO glass at $3000 / \mathrm{min}$. The field emission characteristics of luminance-current, luminance-voltage and luminance-power of Nano-diamond film were analyzed and tested. Comparing these tested curves, the luminance was well proportional to current was got. Theoretic, the inner resistance of NDF field emission display (FED) consumes electric energy and real voltage change between the cathode and the anode of NDF-FED was very small after electrons emit. So the characteristic of NDFFED was preferable to describe by luminance-current linear relationship, which was advantageous to device tested and designed.
\end{abstract}

\section{Keywords}

Nano-Diamond Film (NDF), Sol-Gel Coating Method, Suitable Paste Proportion, Field Emission Display (FED)

\section{Introduction}

Diamond, a wide-band-gap semiconductor material, possesses high hardness, high thermal production, high resistance rate, stable chemical and physical properties, especially the negative electron affinity (NEA) and low work function. Many scientists have extensively studied on the specificity of natural diamond, diamond film, and diamond carbon film [1] [2] [3]. The results indicated that diamond was proper to be used as ideal electron emission cathode material for vacuum microelectronic devices and field emission. Compared with other field emitters, they showed lower emission threshold field and enhanced current capability. Comparing the different diamond films which were fabricated in different methods, many attentions had been put on the field emission application 
of Nano-diamond film (NDF) by chemical vapor deposition (CVD) process. The CVD process and other synthesis of the large area NDF needs long time and high cost, and it was difficult to adulterate impurity [4] [5] [6] [7] [8]. So the sol-gel method was chosen coating NDF. It was found that through adulterated impurity can enhance the electron translocation rate and electron emission efficiency. However, one of these was the control on the electron emission and anode luminance [5] [9] [10] [11] [12]. Through thermal-sintering and post-treatment technique to make diamond emitters, it exposed from NDF to improve field emission stability and emission uniformity. In order to obtain effective luminance control methods, it was necessary to investigate luminescent rule of the NDF for field emission display (FED). If some stated rules want to be gained, theoretical analysis, accurate measure and correct method must be used. In reported some practicable test circuit [13] [14] [15] [16], only power supply voltages were measured. Our group research coated NDF and application to design pressure sensor and so on [17] [18]. In this paper, we present the current-voltage characteristic and anode luminance-voltage characteristic of NDF that both power supply voltage and device voltage were measured at the same time and discuss the anode luminescent rule for NDF.

\section{Sample Fabrication}

\section{Preparation of Electrode}

The poor field emission characteristic was improved by adulterating other material. A low cost Nano-diamond paste was developed by mixing Nano-diamond and Nano-graphite with other inorganic and organic vehicles. Then we used a high mesh to filtrate Nano-diamond paste to remove big grains. Nano-diamond film was fabricated by sol-gel method at $3000 /$ min process as cathode. A series of sol-gel NDF with different proportions were designed for the field emission characteristic test intentionally. NDF was fabricated on indium tin oxide (ITO) glass substrates. The NDF cathode was fixed on substrates by using three-step sintering process. The temperature curve of three-step sintering process for sol-gelled NDF was showed in Figure 1. The post-treatment process want to dismantle a lot leftover layer onto NDF surface and make many Nano-diamond emitters exposed from NDF.

A schematic diagram of the structure and the test-circuit in measurement for NDF sample was showed in previous article. It was a diode-type field-emission device with NDF cathode and phosphor-coated ITO transparent anode, the distance between cathode and anode was $280 \mathrm{um}$. NDF was prepared directly on ITO glass substrate by sol-gel method at $3000 / \mathrm{min}$ process as cathode. The ITO film coated on the base plate was patterned with photolithography as anode and part of the lead. The insulator spacers were constructed by baking and sintering the insulator frit paste that was screen printing on. The inner electric connecting line was sintered from a silver paste strip with the same process as the insulator spacer layer. The phosphor layer was made by almost the same process, except that the phosphor layer did not need to be sintered. The vacuum package was 


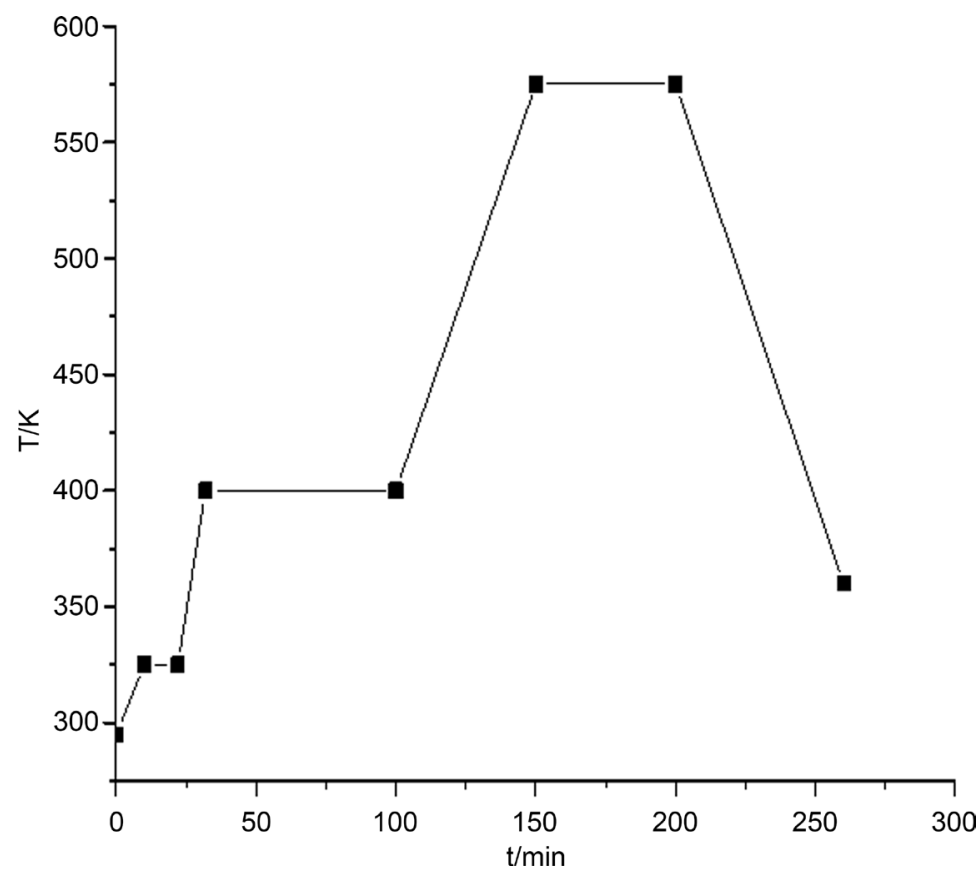

Figure 1. Temperature curve of thermal-sintering for sol-gelled NDF.

fabricated with some vacuum-fluorescence-display-like process technologies. A detailed process can be seen in previous report [10] [17].

The measurement of electron field emission property could be carried out. The test chamber space between the cathode and the anode is about $280 \mu \mathrm{m}$. The inner intensity of pressure was lower than $1.0 \times 10^{-5} \mathrm{~Pa}$, which is an experience value. Electrons emitted from NDF cathode are accelerated and then excite the phosphor on the anode of ITO film lighting. Lighting photo of operating sample was showed in Figure 2.

\section{Testing}

As the gap between NDF cathode and the phosphor layer anode of a NDF -FED was very small, big current-limiting resistance was used generally in testing to avoid device destroying. The resistance between the cathode and the anode measured by ohmmeter, its value was infinity, so the current-limiting resistance was usually neglected and the device voltage was substituted by power supply voltage. When electrons emit at high voltage, the resistance between the cathode and the anode was not infinity, substitute the device voltage with the power supply voltage in characteristic measuring of NDF-FED was unreasonable. In order to clarify the difference, both power supply voltage (U2) and device voltage (U1) were measured at the same time, where the current-limiting resistance was $1 \mathrm{M} \Omega$. The measured dates were showed in Table 1 . The luminance of NDF-FED was measured by the Chroma Model 7100 CRT Color Analyzer. Because the luminescent area was $1 \mathrm{~cm}^{2}$ only, which was smaller than the sense lens area, the data of lightness in Table 1 were the indicating value of the CRT Color Analyzer multiplied by the ratio of the sense lens area to the lighting area. Based on the data in Table 1, the current-voltage characteristic and the lumin- 
ance-voltage characteristic of the sample were showed in Figure 3 and Figure 4, respectively. In Figure 3, there was a big difference between the power supply

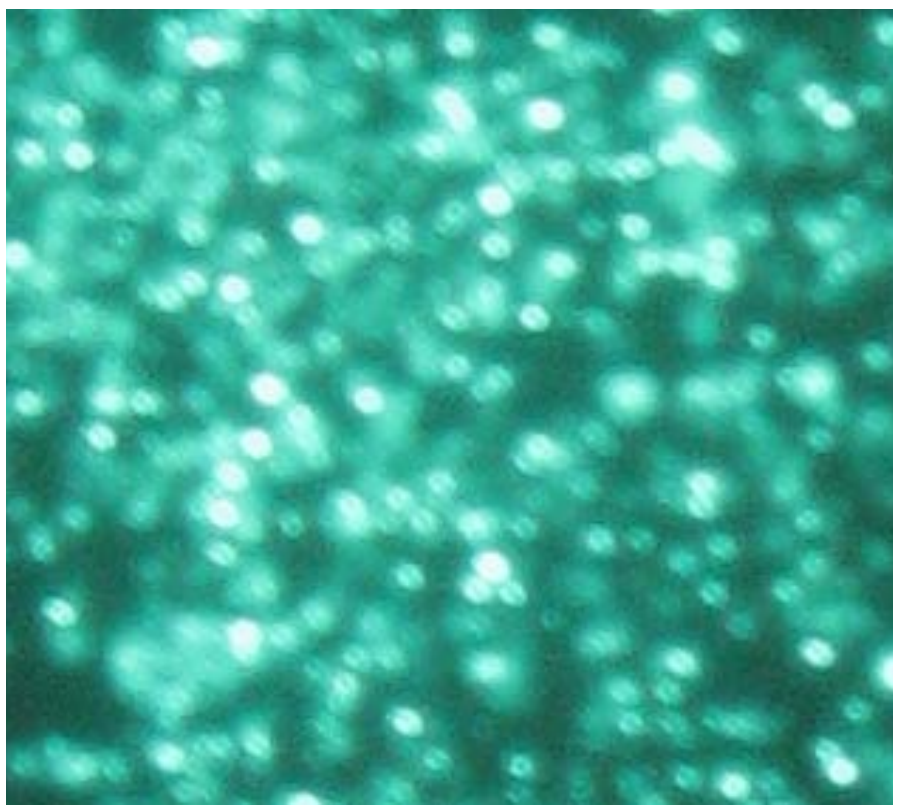

Figure 2. Lighting photo of operating sample.

Table 1. Measured data of the NDF-FED.

\begin{tabular}{cccccccccccccc}
\hline Voltage $\mathrm{U}_{1}(\mathrm{~V})$ & 76 & 92 & 126 & 140 & 151 & 172 & 178 & 188 & 194 & 203 & 210 & 216 & 219 \\
\hline Voltage $\mathrm{U}_{2}(\mathrm{~V})$ & 35 & 96 & 142 & 150 & 168 & 198 & 219 & 260 & 296 & 345 & 380 & 431 & 464 \\
Current $\mathrm{I}(\mu \mathrm{A})$ & 3 & 3.3 & 5 & 5.2 & 5.7 & 7.4 & 8 & 10 & 12.5 & 15.8 & 19.2 & 23.3 & 26.7 \\
$\begin{array}{c}\text { Brightness L } \\
\left(\mathrm{cd} / \mathrm{m}^{2}\right)\end{array}$ & 0.00 & 0.00 & 0.4 & 3.2 & 17.8 & 86 & 182 & 424.8 & 650.6 & 920.2 & 1178 & 1496 & 1800 \\
\hline
\end{tabular}

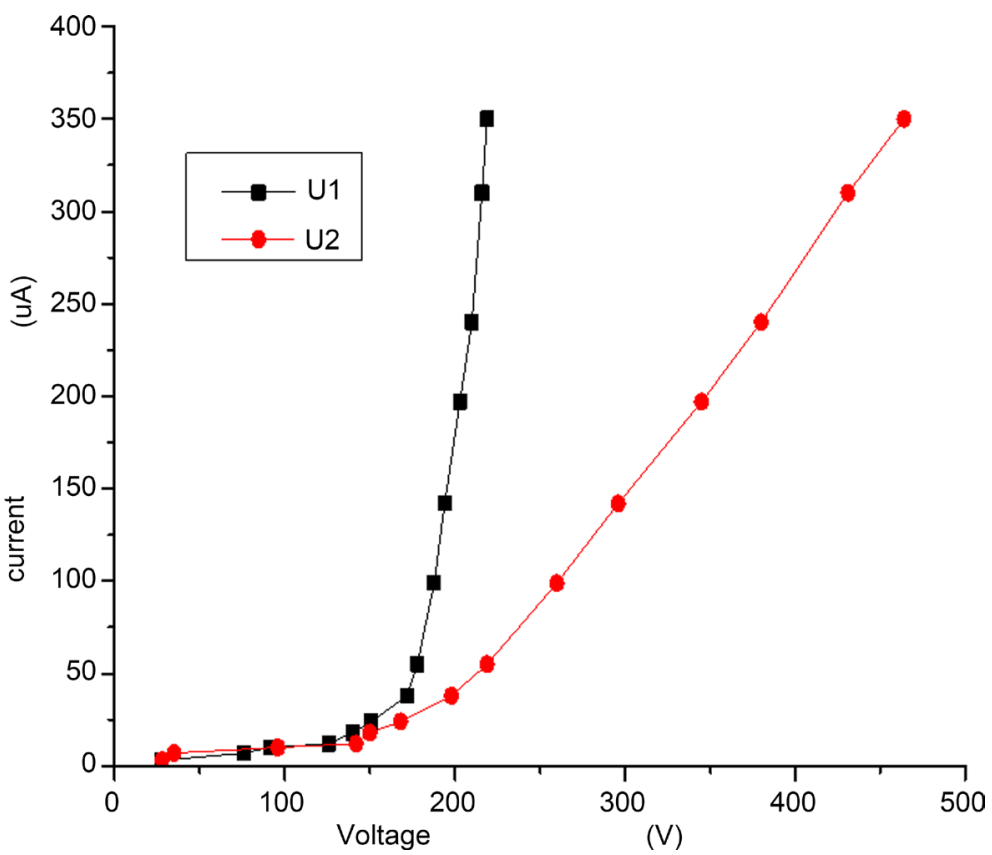

Figure 3. Current-voltage characteristic of the sample. 


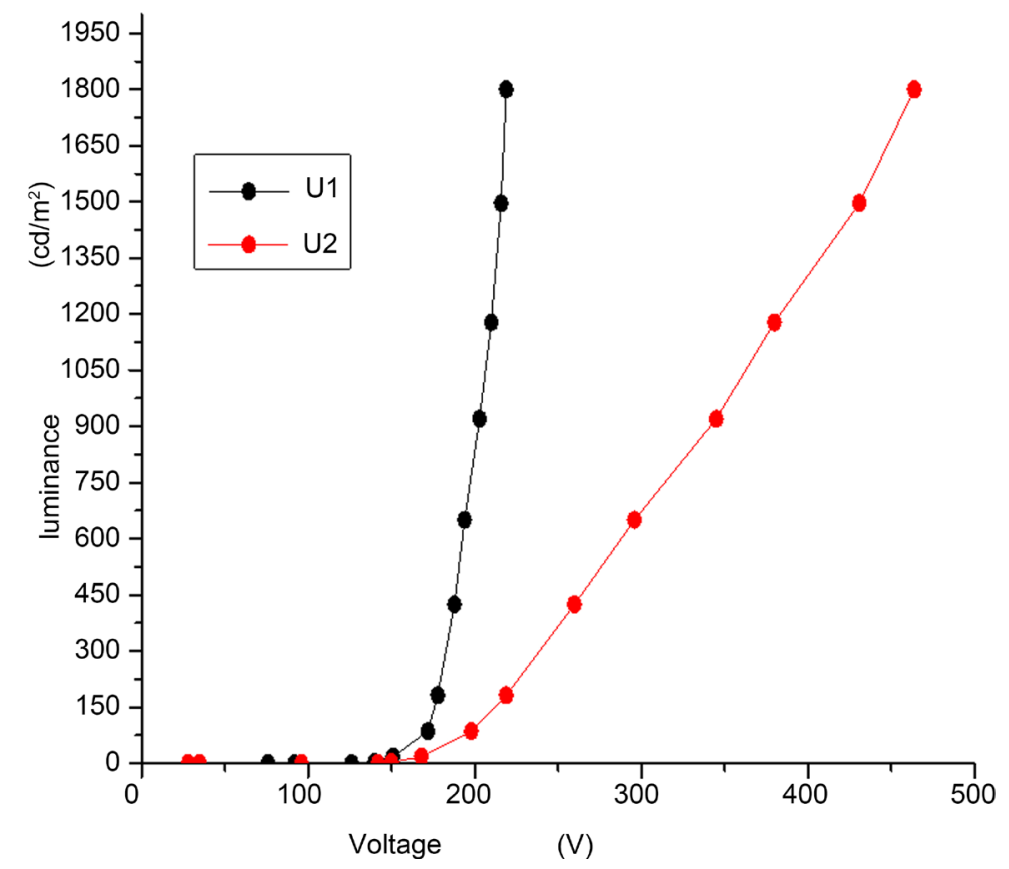

Figure 4. Luminance-voltage characteristic of the sample.

voltage curve and the device voltage curve, so the current-limiting resistance can not be neglected. Characteristic measurement of NDF-FED device must use voltage U1. It was not proper using voltage U2. Current-U1 curve tells that very small change of voltage would create very big change of current. The field emission characteristics of the NDF-FED was analyzed by applying the FowlerNordheim (F-N) equation, $I=a V^{2} \exp (-b / V)$, where $a$ and $b$ were constants.

\section{Luminescent Rule}

In Figure 4, the luminance was approximately proportional to power supply voltage and device voltage, but it was not convenient application because there were big curve slope of luminance-U1 and curve difference of luminance-U2 with different current-limiting resistance. So the curve of luminance versus current was showed in Figure 5 and the curve of luminance versus device power was showed in Figure 6. Obviously, the luminance was well proportional to current. In Figure 6, the luminance was approximately proportional to device power IU1, but it was not proportional to drive power IU2.

The reasons of these curve formation were analyzed as followed: On the one hand, because of light coming from the phosphor excited by electrons, the luminance must be proportional to the number of electrons that bombard phosphor. Namely, the luminance of NDF-FED must be proportional to current. On the other hand, the energy of an electron gained from electrical field was about

$$
e V=1.60 \times 10-19 \times 250=4 \times 10-17(J)
$$

The required energy for excited a photon is about

$$
h v=6.63 \times 10-34 \times 3 \times 108 /(6 \times 10-7)=3.315 \times 10-19(J)
$$




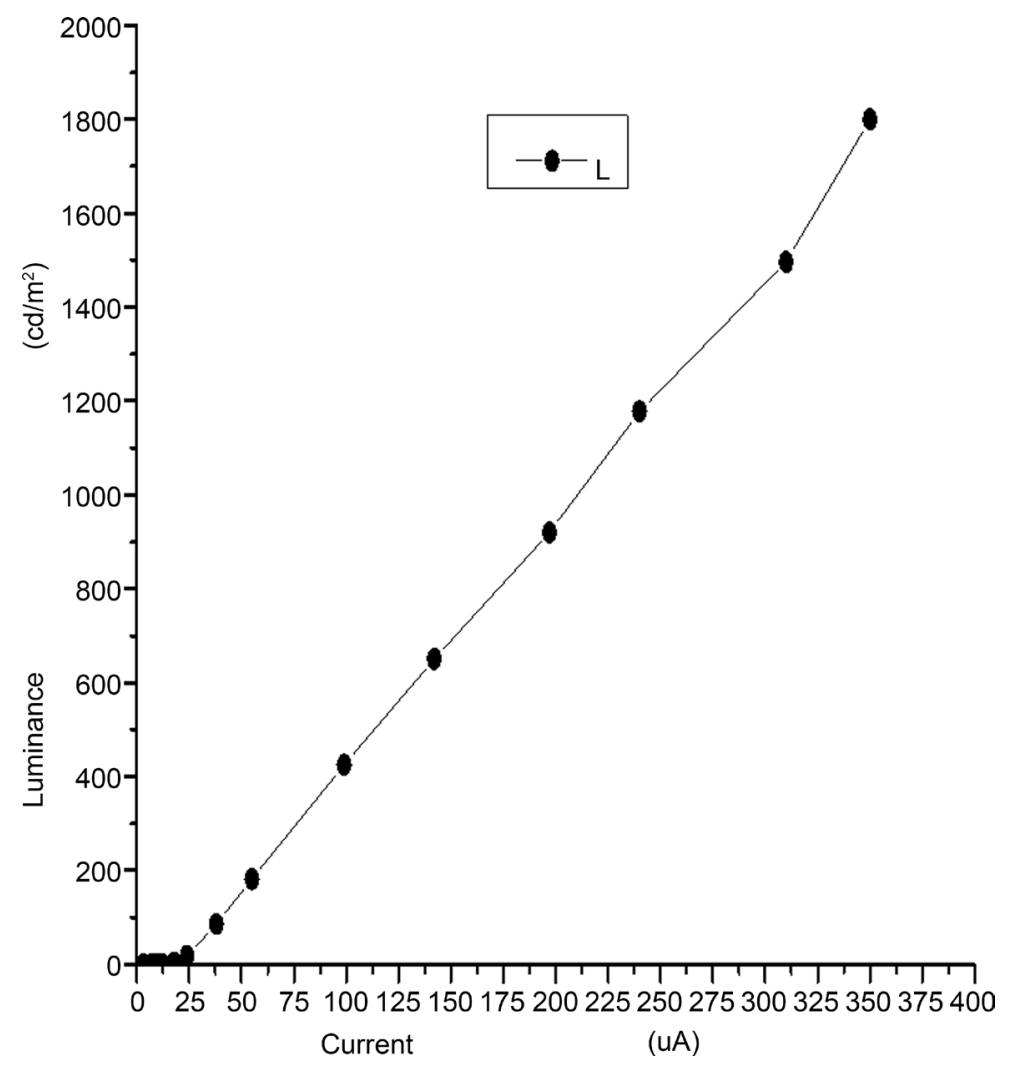

Figure 5. Luminance of NDF-FED with current.

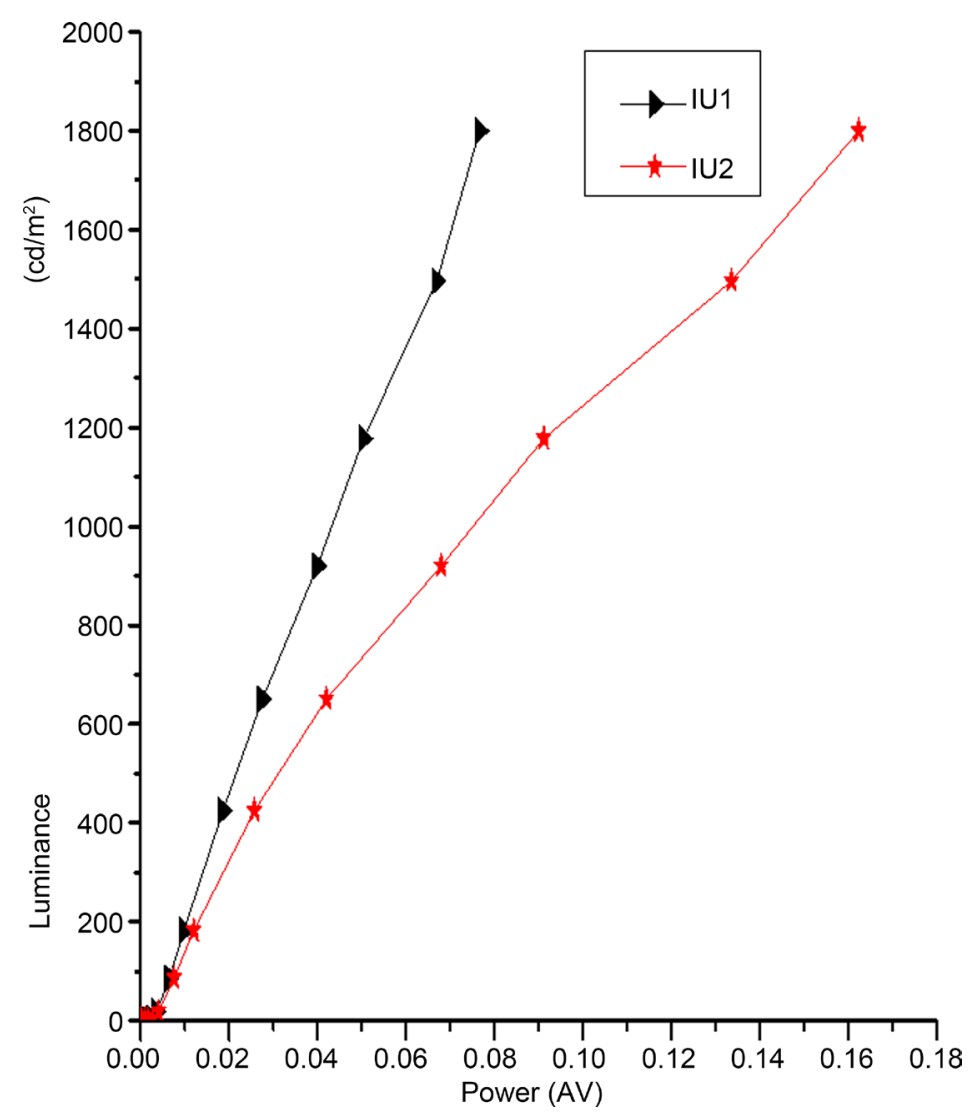

Figure 6. Luminance of NDF-FED with power. 
So an electron maybe creates many photons. Because the energy of electrons gained from electrical field was proportional to device voltage, the luminance must be proportional to device voltage. Therefore, the luminance must be proportional to device power. This was a theoretical conclusion. In fact, because there were phosphor and semiconductor silicon wafer in NDF-FED device, a certain resistance exists in the device. The equivalent circuit was showed in Figure 7, where a NDF-FED device was equal to a FED and an inner resistance Ri. The inner resistance $\mathrm{Ri}$ creates consequentially a certain voltage drop in circuit.The device voltage in test must include this partial voltage drop. Seen from field electron emission, real curves must be steeper than measure curves in Figure 3 and Figure 4. The inner resistance Ri consumes electric energy, but this electric energy consumption creates heat instead of light. As a result, the luminance was not well proportional to device power. According to electric field theory, the relationship of the charge planar density $\sigma_{e}$ and electric field intensity $E$ follow the formula before the electron emission: $\sigma_{e}=\varepsilon E=\varepsilon U / d$.

$U$ is voltage drop between the cathode and the anode, $\varepsilon$ is dielectric constant, and $d$ is the spacing interval between the cathode and the anode. According to the field electron emission theory, when the electric field intensity reaches the threshold, electrons will emit from Nano-diamond. Namely, the electron emission occurs only when the accumulation of charge on the surface of emitter reaches a certain degree. The electron emission, however, will reduce the electric field intensity on the surface. So, the value of electric field intensity was approximately fixed and real voltage change between the cathode and the anode of a NDF-FED is very small after electrons emit. Based on these analyses, it was more proper to describe the characteristic of a NDF-FED by luminance-current linear relationship.

\section{Summary}

A diode-type field-emission device with Nano-diamond film cathode was fabricated by the vacuum-fluorescent-display-like package processes. Nano-diamond film was fabricated by sol-gel method at $3000 /$ min process as cathode. Very ideal

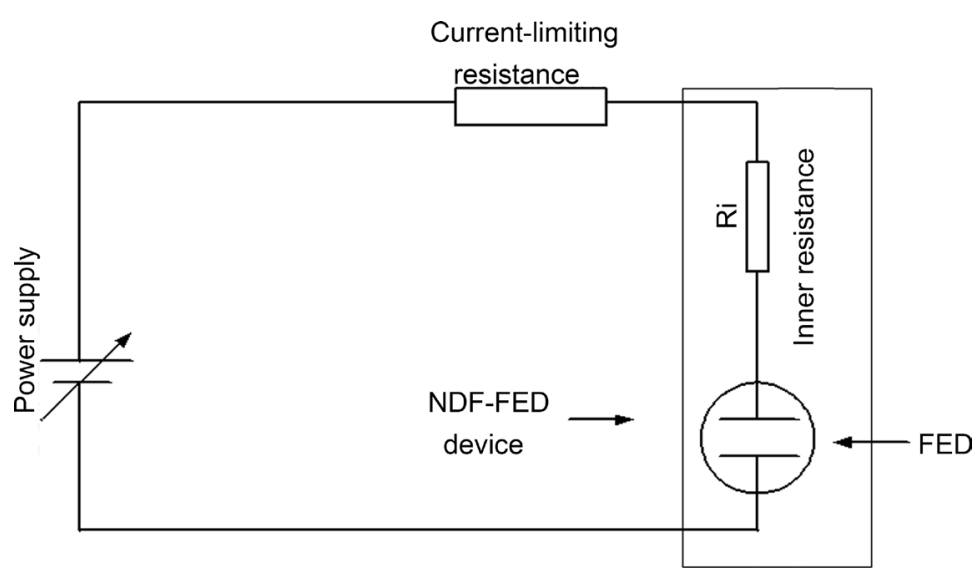

Figure 7. The equivalent circuit. 
current-voltage characteristic and luminance-voltage characteristic of NDF-FED are obtained for measuring the device voltage. It was found that substituting power supply voltage for device voltage was unreasonable. Comparing luminance-current curve with luminance-voltage curve and luminance-power curve, it was found that the luminance was well proportional to current. Theoretical analysis showed that the reasons were the inner resistance of NDF-FED consumes electric energy and real voltage change between the cathode and the anode of NDF-FED was very small after electrons emit. Hence, the characteristic of NDFFED was preferable to describe by luminance-current linear relationship, which was advantageous to device tested and designed.

\section{Acknowledgements}

The project was supported by the National Natural Science Foundation of China (51365001).

\section{References}

[1] Xu, N.S., Latham, R.V. and Tzeng, Y. (1993) Field-Dependence of the Area-Density of "Cold" Electron Emission Sites on Broad-Area CVD Diamond Films. Electronics Letter, 29, 1596-1597. https://doi.org/10.1049/el:19931063

[2] Hu, X.J., Chen, C.K. and Lu, S.H. (2016) High Mobility n-Type Conductive Ultrananocrystalline Diamond and Graphene Nanoribbon Hybridized Carbon Films. Journal of Carbon, 98, 671-680.

[3] Mertens, M. and Mohr, M. (2015) N-Type Conductive Ultrananocrystalline Diamond Films Grown by Hot Filament CVD. Journal of Nanomaterials, 26, 1-6. https://doi.org/10.1155/2015/527025

[4] Xu, N.S., Tzeng, Y. and Latham, R.V. (1993) Similarities in the "Cold" Electron Emission Characteristics of Diamond Coated Molybdenum Electrodes and Polished Bulk Graphite Surfaces. Journal of Physics D: Applied Physics, 26, 1776-1780. https://doi.org/10.1088/0022-3727/26/10/035

[5] Gracio, J.J., Fan, Q.H. and Madaleno, J.C. (2010) Diamond Growth by Chemical Vapour Deposition. Journal of Physics D: Applied Physics, 43, 374017.

[6] Yang, X.C. and Zhang, X.X. Research of Nano-Diamond Film Prepared on Solar Cell Window. Applied Mechanics and Materials.

[7] Shenderova, O.A., Zhirnov, V.V. and Brenner, D.W. (2002) Carbon Nanostructures. Critical Reviews in Solid State and Materials Sciences, 27, 227. https://doi.org/10.1080/10408430208500497

[8] Vul, A., Dolmatov, V. and Shenderova, O. (2003) Detonation Nanodiamonds and Related Materials. FIZINTEL, S. Petersburg, Russia.

[9] Gruen, D., Vul, A. and Shenderova, O. (2005) Ultrananocrystalline Diamond: Synthesis, Properties and Applications. NATO Science Series, Kluwer Academic Publishers.

[10] Achatz, P., Garrido, J.A., Stutzmann, M., Williams, O.A., Gruen, D.M., Kromka, A. and Steinmüller, D. (2006) Optical Properties of Nanocrystalline Diamond Thin Films. Applied Physics Letters, 88, Article ID: 101908. https://doi.org/10.1063/1.2183366

[11] Williams, O.A., Nesladek, M., Daenen, M., Michaelson, S., Hoffman, A., Osawa, E., Haenen, K. and Jackman, R.B. (2008) Growth, Electronic Properties and Applica- 
tions of Nanodiamond. Diamond and Related Materials, 17, 1080-1088. https://doi.org/10.1016/j.diamond.2008.01.103

[12] Kang, W.P., Davidson, J.L., Wisitsora-at, A., Wong, Y.M., Takalkar, R., et al. (2004) Diamond Vacuum Field Emission Devices. Diamond and Related Materials, 13, 1944-1948. https://doi.org/10.1016/j.diamond.2004.07.024

[13] Abbas, G., Roy, S., Papakonstantinou, P. and McLaughlin, J.A. (2005) Structural Investigation and Gas Barrier Performance of Diamond-Like Carbon Based Films on Polymer Substrates. Carbon, 43, 303-308. https://doi.org/10.1016/j.carbon.2004.09.016

[14] Zhang, X. and Zhu, C. (2006) The Fabrication of Novel Structure of Field Emitting Light Tube with Carbon Nanotubes as Cathode. 19th International Vacuum Nanoelectronics Conference, 50 th International Field Emission Symposium, Vol. 2, Guilin, 1 January 2006, 329-330.

[15] Wong, Y.M., Kang, W.R., Davidson, J.L. and Huang, J.H. (2007) Performance Enhancement of Carbon Nanotubes Vacuum Field Emission Triode Amplifier by Post-Synthesis Treatment. Diamond and Related Materials, 16, 1403-1407. https://doi.org/10.1016/j.diamond.2007.01.039

[16] Subramanian, K., Kang, W.P., Davidson, J.L. and Choi, B.K. (2008) The Effect of Interelectrode Spacing on Field Emission in Nanodiamond Lateral Vacuum Devices. Diamond and Related Materials, 17, 1808-1811. https://doi.org/10.1016/j.diamond.2008.04.004

[17] Zhang, X., Wei, S., Lei, C., et al. (2011) Application of Printed Nanocrystalline Diamond Film for Electron Emission Cathode. Applied Surface Science, 257, 5185 5189. https://doi.org/10.1016/j.apsusc.2010.10.067

[18] Zhang, X., Wang, E. and Yang, X. (2014) Design and Simulation of NANO-Diamond Film Pressure Sensor. Vacuum, 99, 189-191. https://doi.org/10.1016/j.vacuum.2013.05.023

Submit or recommend next manuscript to SCIRP and we will provide best service for you:

Accepting pre-submission inquiries through Email, Facebook, LinkedIn, Twitter, etc. A wide selection of journals (inclusive of 9 subjects, more than 200 journals)

Providing 24-hour high-quality service

User-friendly online submission system

Fair and swift peer-review system

Efficient typesetting and proofreading procedure

Display of the result of downloads and visits, as well as the number of cited articles

Maximum dissemination of your research work

Submit your manuscript at: http://papersubmission.scirp.org/

Or contact anp@scirp.org 